\title{
Ediclea Santos: a voz da mulher negra que faz Passarinho cantar mais alto
}

Ediclea Santos: the voice of the black Woman that makes The Bird sing louder

Maria Cristina do Nascimento ${ }^{1}$

1 Secretaria de Educação do Recife - Grupo de Trabalho em Educação das Relações Étnico-raciais - GTERÊ, Rede de Mulheres Negras de Pernambuco, Grupo de Pesquisa GEPERGES - Grupo de Estudos e Pesquisas em Educação, Raça, Gênero e Sexualidades Audre Lorde - UFRPE, E-mail: critina.nascimento@prof.educ.rec.br; ORCID: https://orcid.org/0000-0003-2129-6966

ART ICLE INFO

Article history:

Received 2021-06-30

Accepted 2021-08-02

Available online 2021-08-02
Palavras-chave: Mulher negra. Dororidade. Racismos. Feminismo negro. Escrevivências.

Keywords: Black woman. Pain of the black woman. racisms. Black feminism. Black women's lives writings.

RESUMO. Este é mais um escrito (temos muitos e virão outros de muitas outras) de uma mulher negra que reconhece outra mulher negra como inspiração pra ação, pra luta e pra reflexão epistemológica. É também um diálogo com Audre Lorde sobre a transformação do silêncio em ação e a organização da raiva pelas mulheres negras em ação política e transformadora, configura-se num passeio pela potência gerada da Dororidade (Vilma Piedade) e nas escrevivências (Conceição Evaristo). Nossa personagem é feminista, mulher negra, periférica, cantora, atriz, mãe de 03 filhos e uma filha, é também avó. Ediclea Santos (Clea) a mulher negra que faz o canto das mulheres de Passarinho, seu bairro, entoar forte e ecoar além dos muros locais. Clea tem uma chama pro canto, pra coletividade, pro ajuntamento de vozes silenciadas, mas ela não canta nem fala pelas outras, ela articula, movimenta, instiga e provoca agitos. É uma das organizadoras do Espaço Mulher de Passarinho (antes as Kombeiras), do Ocupe Passarinho, seu ativismo se articula no Fórum de Mulheres de Pernambuco, na Rede de Mulheres Negras de Pernambuco, na Articulação de Mulheres Brasileiras e vem fazendo costuras e misturas democráticas com diversos movimentos. É sobre potências negras, é sobre a transformação da dor em potência, sobre ética e poética das mulheres negras.

ABSTRACT. This is another writing (we have many and others will come from many others women's) by a black woman who recognizes another black woman as an inspiration for action, struggle and epistemological reflection. It is also a dialogue with Audre Lorde about the transformation of silence into action and the organization of anger by black women into political and transformative action, configured in a tour of the power generated by pain of the black women (Dororidade by Vilma Piedade) and black women's lives writings (Escrevivências by Conceição Evaristo). Our character is 
a feminist, black woman, peripheral, singer, actress, mother of 03 children and one daughter, she is also a grandmother. Ediclea Santos (Clea) the black woman who sings the women of Passarinho, her neighborhood, singing loudly and echoing beyond the local walls. Clea has a flame for the singing, for the community, for the gathering of silenced voices, but she doesn't sing or speak for others, she articulates, moves, instigates and provokes agitation. She is one of the organizers from the Espaço Mulher de Passarinho (formerly the Kombeiras), of Ocupe Passarinho, her activism is articulated in the Pernambuco Women's Forum (FMPE), in the Black Women's Network of Pernambuco (RMNPE), in the Articulation of Brazilian Women (AMB), and has been making democratic sewings and mixtures with different movements. It's about black potencies, it's about transforming pain into potency, about black women's ethics and poetics.

\section{Introdução}

Considero que escrever histórias de vida de mulheres negras não é uma escolha, é uma imperiosa necessidade que tem como pressuposto que estas histórias são repotencializadoras da energia vital e me/nos conecta em ancestralidade coletiva. São histórias potentes que funcionam como nutrientes de força e resistência de outras mulheres negras. Conceição Evaristo cunhou o termo escrevivência, afirmando que:

Sendo as mulheres negras invisibilizadas, não só pelas páginas da história oficial brasileira, mas também pela literatura, e quando se tornam objetos da segunda, na maioria das vezes, surgem ficcionalizadas a partir de estereótipos vários, para as escritoras negras cabem vários cuidados. Assenhoreando-se "da pena", objeto representativo do poder falo-cêntrico branco, as escritoras negras buscam inscrever no corpus literário brasileiro imagens de uma autorepresentação. Surge a fala de um corpo que não é apenas descrito, mas antes de tudo vivido. A escre(vivência) das mulheres negras explicita as aventuras e as desventuras de quem conhece uma dupla condição, que a sociedade teima em querer inferiorizada, mulher e negra (EVARISTO, 2005, p. 06).

E é nele que me apoio para esse diálogo aqui tracejado. Precisamos falar de nós e de nós outras, porque há muitas de nós em cada uma de nós mesmas (a repetição foi desejada para dar a ênfase necessária, desculpem as quebras de algumas preciosidades linguísticas).

Também me apoio em Audre Lorde (2019) mulher negra poeta, intelectual, lésbica, que afirmou em seus escritos a importância de transformar a raiva em potência e em luta porque, como mulher negra, lésbica, mãe, num casamento interracial, percebia os entrecruzamentos de opressões e a necessidade de lutar contra todas elas, sem hierarquizar pressões e utilizando o poder da linguagem na resistência:

Cada uma de nós está aqui hoje porque, de uma forma ou de outra, compartilhamos um compromisso com a linguagem, com o poder da linguagem e com o ato de ressignificar essa linguagem que foi criada para operar contra nós. Na transformação do silêncio em linguagem 
e em ação, é essencial que cada uma de nós estabeleça ou analise seu papel nessa transformação e reconheça que seu papel é vital nesse processo (LORDE,2019, p. 54).

Mesmo debruçada sobre esse desejo de me inscrever a partir dos cânones coloniais, há muito de mim que ainda duvida, porque fui forjada numa sociedade culturalmente sexista e machista que me ensinou a pensar que eu não era capaz e nem tinha o que dizer de mim, nem de mulheres de parecença comigo. Por isso, já que escrevo, ousarei um cadinho de transgressão acadêmica.

Nesses encontros e entre dores compartilhadas me fortaleço no conceito de Dororidade, com letra maiúscula, como a autora do termo estabelece, apresentando esse lugar-comum das dores das mulheres negras, atravessadas pelos racismos e sexismos, estruturadores do imaginário (estereótipos e estigmas), das relações interpessoais, relações de poder, da economia, aos quais somos apresentadas e definidas logo que nascemos negras mulheres.

\section{Desenvolvimento}

Quando conheci Clea, sua voz forte me impressionou, sua história na luta pela moradia e sua forma desafiadora de estar no mundo me marcaram profundamente. Foi no final dos anos 90, onde ela atuava como atriz no grupo de teatro feminista Loucas de Pedra Lilás, convivemos por quase uma década, nesse mesmo grupo, construímos parcerias, muitas trocas e aprendizagens e alguns embates necessários para nossos crescimentos. Para essa escrita, conversamos pelo Google Meet e combinamos de ir nos comunicando pelo WhatsApp em relação à proposta de eu escrever sobre ela, por que me foi solicitado escolher uma mulher negra para fazer um verbete em um dicionário e, das muitas que conheço, apaixonei-me pela possibilidade de visibilizar mais a beleza e a potência dessa mulher plural, nessas trocas, solicitei que ela ficasse à vontade para falar de si mesma e dela com as outras:

Ediclea Santos é uma mulher negra, periférica, de 64 anos, divorciada, mãe de 04 filhos, seis netos, fui criada com a minha vó e meu pai. minha dizia e minha vó também me falava, com três meses meus pais se separaram que, mas teve uma filha antes de mim, mas morreu bem bebezinha ainda, depois veio eu e aí eles se separaram e eu fiquei com minha vó. (SANTOS, entrevista, 2021).

Clea tem uma chama pro canto, pra coletividade, pro ajuntamento de vozes silenciadas, mas ela não canta nem fala pelas outras, ela articula, movimenta, instiga e provoca agitos.

Neste país, onde diferenças raciais criam uma constante, ainda que velada, distorção de visões, as mulheres negras, por um lado, sempre foram altamente visíveis, assim como, por outro lado, foram invisibilizadas pela despersonalização do racismo. Mesmo dentro do movimento social das mulheres, nós tivemos que lutar, e ainda lutamos, por essa visibilidade, que é também o que nos torna mais vulneráveis - a nossa negritude. Para sobrevivermos na boca desse dragão que chamamos de américa, tivemos de aprender esta primeira lição, a mais vital: que a nossa sobrevivência nunca fez parte 
dos planos. Não como seres humanos. Incluindo a sobrevivência da maioria de vocês aqui hoje, negras ou não. E essa visibilidade que nos torna mais vulneráveis é também a fonte de nossa maior força. Porque a máquina vai tentar nos reduzir a pó de qualquer maneira, quer falemos, quer não. Podemos ficar eternamente caladas pelos cantos enquanto nossas irmãs e nós somos diminuídas, enquanto nossos filhos são corrompidos e destruídos, enquanto nossa terra é envenenada; podemos ficar caladas a salvo nos nossos cantos, de bico fechado, e ainda assim nosso medo não será menor (LORDE, 2019, p.53/54).

\subsection{A raiva mobilizando a luta}

Com sua voz potente e argumentação contundente ela já foi acusada de ser "braba", mas muitas mulheres negras já ouviram algo semelhante, quando afrontamos o sistema, colocando nossa voz e denunciando as tentativas de silenciamentos. E a grandiosidade está em transformar essa raiva em luta coletiva, raiva transformada em ação:

Minha raiva é uma resposta às atitudes racistas e às ações e presunção que surgem dessas atitudes. Se você lidar com outras mulheres reflete essas atitudes, então minha raiva e seus medos são focos que podem ser usados para crescimento, da mesma forma em que eu usei aprender a lidar com a raiva para o meu crescimento. Mas para controle de danos, não para culpa. Culpa e defensividade são tijolos numa parede contra a qual todas nós batemos; ela não serve a nenhum de nossos futuros. (LORDE, 2019, p.157).

Quando pergunto sobre esse sentimento, ela afirma que não tem raiva e, na dialogicidade, nos entendemos não se se tratar da raiva/rancor, porque esta é uma raiva que adoece, o contrário ocorre com a da raiva/indignação, como processo de cura, que nos impulsiona para a ação e para a mudança. É sobre isso que Audre Lorde nos fala, e considero que a resposta para este sentimento está na organização da luta coletiva, na articulação e nos enredamentos e re/existências:

Mulheres respondendo ao racismo significa mulheres respondendo a raiva; raiva da exclusão, dos privilégios não questionados, das distorções raciais, do silêncio, do maltrato, esteriotipização, defensividade, má nomeação, traição e captação. (LORDE, 2019, p.157)

Ediclea Santos é uma das primeiras moradoras de Passarinho, um bairro que fica na zona norte, entre Recife e Olinda, e mesmo com pouco mais de 30 anos, é considerado um dos bairros mais habitados da Região Metropolitana do Recife, algumas de suas ruas entoam nomes de pássaros (Anum, Concriz, Bem-te-vi, Arara, Beija-flor), num canto pouco escutado pelos fazedores de políticas públicas. Um bairro que teve como berço o Morro da Conceição onde nasceu ela e de onde saíram (também do Alto José Bonifácio, Santa Terezinha), centenas de famílias, em situação de risco e/ou desabrigamento, num movimento de reivindicação de direito à moradia. 
Não foi fácil. Quando fundamos o grupo, nenhuma tinha ouvido falar de feminismo. Nenhuma viajava sozinha, sem filho ou marido. $\mathrm{Na}$ caminhada começamos a sair de casa, viajar para Brasília (DF) fazer luta, participar de encontros nacionais. E fomos descobrindo nas bocas de outras mulheres as nossas histórias e nos tornando feministas (SANTOS, Entrevista, 2019).

Segundo Vilma Piedade (2017), a Dororidade rompe o determinismo histórico, em relação aos destinos ligados à raça, lugares e não-lugares, que os racismos nos impõem, neste sentido, ela potencializa o rompimento da possibilidade de apenas um lado da história ser contado.

Alguns até dizem 'a senhora só fala das mulheres'. E eu respondo: vocês se reúnam, formem um grupo de homens. Enquanto a gente se reunia na kombi para falar de política pública para trazer melhorias, vocês se reuniam para falar de cachaça, de dominó e de futebol (SANTOS, Entrevista Brasil de Fato, 2019).

Uma mulher que escolheu não ficar calada, foi compreendendo em sua trajetória que, para ser ouvida, precisava ampliar seu canto de libertação junto a outras, que como ela, viviam situações de negação de direitos e violências estruturais e raciais, a Dororidade as uniu, a Dororidade alinhou as dores e deu novas cores às falas e lutas, o reconhecimento da negritude e o aprofundamento sobre as raízes histórico-sociais do racismo e do sexismo foram potencializador do crescimento do Espaço Mulher de Passarinho:

[...] E aí conheci o movimento já nos anos 80, 80 e 85/84 por aí, quando eu morava no Morro, [...] conheci o movimento de mulheres no grupo de mulheres do Morro da Conceição, na época do tíquete de leite e daí não saí mais, né, fui, participei de lá do grupo com as meninas e fazendo reuniões em vários locais lá do morro aí e depois entrei nas grupo loucas de pedra lilás em 90 , nos anos 90 , também, acho que em 97 e aí passei 10 anos nas loucas, vim pra Passarinho e aí foi quando a gente fundou esse grupo de mulheres daqui que a gente também foi se reconhecendo como mulheres negras e desde que eu entrei no movimento não saí mais [..] eu fui me encantando com o movimento de mulheres, por aí a questão de violência, tudo isso eu fui, eu não sabia nada disso, aprendi tudo sobre o racismo, violência tudo no movimento de mulheres (SANTOS, entrevista, 2021).

O en/cantamento escrevivido por Ediclea, passados tantos anos, é contínuo e sistemático, ampliado e sempre envolvendo outras/outros e outres. Trago aqui um pouco desses enlaces: Kombeiras/Espaço Mulher de Passarinho, Ação Beleza Negra, Bloco Carnavalesco Sou Gorda, mas eu pulo, Articulação de Lutas Pré-Ocupe e Ocupe Passarinho.

\subsection{Das Kombeiras ao Espaço Mulher de Passarinho}

Investindo contra várias formas de silenciamento, as mulheres negras continuam buscando se fazerem ouvir na sociedade brasileira, 
conservadora de um imaginário contra o negro. Imagens nascidas de uma sociedade escravocrata perpassam, até hoje, profundamente, pelos modos das relações sociais brasileiras (EVARISTO, 2005, p. 5).

Com outras mulheres, durante deslocamento para o centro da cidade e o retorno, no único transporte possível, a kombi, trabalhadoras domésticas, diaristas, em sua maioria, entre as narrativas pessoais e coletivas frente às dificuldades enfrentadas no cotidiano: água, segurança, educação, transporte, se autodenominaram "As kombeiras", 1999 que mais tarde, 2003, mudou para Espaço Mulher de Passarinho, assim ela nos conta:

A gente ia conversando sobre possíveis melhorias para o bairro [...]. Tudo o que temos aqui foi através da luta: a única escola que temos, o único posto de saúde que temos e o transporte também foi pela reivindicação

Porque nós mulheres negras nos reconhecemos e nos afirmamos coletivas a partir da Dororidade, essa dor e nem sempre delícia de se saber ou não saber o que somos, como escurece a Vilma Piedade (2017), quando afirma que a faxina tem cor, é negra e tá no dicionário. Ediclea relembra a participação de Lenira Carvalho, nos processos de formação do Espaço Mulher, uma importante liderança nacional, em defesa dos direitos das trabalhadoras domésticas, fundadora nos anos 70, da Associação das Empregadas Domésticas da Região Metropolitana do Recife,

[...] Lenira vinha uma vez no mês a conversar com as domésticas aqui na comunidade e foi daí que a gente começou a organizar esse grupo, sempre, sempre chamando pessoas do movimento pra vir nos fortalecer, né, porque a gente pode até se fortalecer sozinha, mas quando está em grupo a gente se fortalece muito mais (SANTOS, entrevista, 2021),

A afirmação dessa voz contundente tem se dado em vários espaços de visibilização das lutas, com reconhecimento principalmente nos movimentos de mulheres de Pernambuco (Fórum de Mulheres, Rede de Mulheres Negras, Organização de mulheres de bairros...) com entrevistas, parcerias em torno das questões da comunidade, articuladas no Ocupe Passarinho e maior aglutinação de pessoas da própria comunidade, que reconhece nela e no Espaço Mulher de Passarinho essa potência e liderança.

O Ocupe Passarinho constitui-se numa grande articulação, impulsionada pelo Espaço Mulher de Passarinho, em movimento por direitos para o bairro, com uma gama imensa de parceiras e colaborações, incluindo estudantes, artistas, jovens e crianças da comunidade, organizações feministas e negras.

Ocupe Passarinho teve inspiração no Ocupe Estelita, um movimento recifense pelo direito à cidade, tem como objetivo a mobilização pelo direito à moradia para 5 mil famílias e por um bairro mais limpo, bonito, verde e iluminado! O primeiro aconteceu no dia 10 de outubro de 2015, com ações preparatórias - o Pré-Ocupe em que temas de interesse são debatidos, tais como organização comunitária, direito à cidade, agricultura urbana, segurança alimentar, educação pública e de qualidade outros... e vem se renovando e se adaptando, inclusive em tempos de Pandemia (2020-2021). 


\section{Conclusão}

Para Conceição Evaristo (2005) escrever constitui-se numa espécie de vingança e/ou desafio, visto que, a memória e a história são registros de quem sempre ocupou o poder:

Gosto de escrever, na maioria das vezes dói, mas depois do texto escrito é possível apaziguar um pouco a dor, eu digo um pouco... Escrever pode ser uma espécie de vingança, às vezes fico pensando sobre isso. Não sei se vingança, talvez desafio, um modo de ferir o silencio imposto, ou ainda, executar um gesto de teimosa esperança. Gosto de dizer ainda que a escrita é para mim o movimento de dançacanto que o meu corpo não executa, é a senha pela qual eu acesso o mundo (EVARISTO, 2005, p.02).

Penso ser muito importante que possamos nos convidar, cada vez mais, a compor memórias e histórias de mulheres negras em cada cantinho do Brasil, para enegrecer a escrita e as escrituras e, dessa forma, redesenhar a poética da existência e da resistência, assinalando caminhos de boniteza e de alegria ancestral, alegria negra e diaspórica.

Ediclea Santos, essa grande mulher negra, organiza a raiva, sem perder a alegria, potencializada em encontros, trocas e irmandades, rompe silêncios, tendo a Dororidade como força motriz para alçar voos mais altos e cantos de transformação de realidades adversas, com atravessamentos do racismo, sexismo e desigualdades sociais.

\section{REFERÊNCIAS}

EVARISTO, Conceição. Gênero e Etnia: uma escre(vivência) de dupla face. In Mulheres no Mundo - Etnia, Marginalidade e Diáspora, Nadilza Martins de Barros Moreira \& Liane Schneider (orgs), João Pessoa, UFPB, Idéia/Editora Universitária, 2005. PDF.

LORDE, Audre. Irmã outsider. tradução Stephanie Borges. -- 1. ed. -- Belo Horizonte: Autêntica Editora, 2019.

PIEDADE, Vilma. Dororidade. São Paulo, Editora Nós, 2017.

SANTOS, Ediclea. Tudo o que temos é fruto do trabalho e da luta do povo que mora aqui. Entrevista concedida a Vinicius Sobreira. Brasil de Fato PE. Recife, 23 de dezembro de 2019.2 Disponível em: https://www.brasildefatope.com.br/2019/12/23/tudo-o-que-temos-e-fruto-do-trabalhoe-da-luta-do-povo-que-mora-aqui .Acesso em 14 de junho de 2021.

SANTOS, Ediclea. Entrevista concedida a autora por whatsapp. Recife, 2021. 